\title{
Correction to: Optometry in South-East Asia
}

Kovin Naidoo, Anitha Arvind, Carmen Abesamos-Dichoso, Kah Ooi Tan, and Pirindha Govender-Poonsamy

\section{Correction to: Chapter 18 in T. Das, P. D. Nayar (eds.), South-East Asia Eye Health, https://doi.org/10.1007/978-981-16-3787-2_18}

The book was inadvertently published with the error in the affiliation of K. O. Tan as Hong Kong and now it is updated as Singapore with this erratum. 